\title{
Experimental Study on Static and Dynamic Compression Mechanical Properties of Filled Rock Joints
}

\author{
Shaobo Chaia,b,c* iD, Hao Wang ${ }^{a}$ (D) , Liyuan Yü (D), Jiehui Shi ${ }^{a}$ iD, Erdi Abi \\ a School of Civil Engineering, Chang' an University, Xi'an, 710064, China. E-mail: shbchai@chd.edu.cn, 2017128017@chd.edu.cn, \\ 2019228016@chd.edu.cn \\ b State Key Laboratory for GeoMechanics and Deep Underground Engineering, China University of Mining \& Technology, Xuzhou, 221116, \\ China. E-mail: yuliyuan@cumt.edu.cn \\ c School of River \& Ocean Engineering, Chongqing Jiaotong University, Chongqing, 400045, China. E-mail: abierdi@163.com
}

* Corresponding author

https://doi.org/10.1590/1679-78255988

\begin{abstract}
The static and dynamic compression mechanical properties of the prefabricated artificial filled rock joints specimens with different fillings and different joint thicknesses are tested, respectively. Then, the strength, deformation, wave propagation and energy dissipation laws of the filled joints are analyzed. The experimental results show that the static and dynamic compression strength of filled joints increases with the strength of filling materials while decreases with the filling thickness. The deformation characteristics of filled joints under static and dynamic compression are positively correlated with the properties of filling materials and the thickness of filled joints. With the increasing of the filling thickness, the reflection coefficient increases while the transmission coefficient decreases. With the increase of the strength of the fillings, the reflection coefficient decreases while the transmission coefficient increases. The energy dissipation ratio decreases with the increase of the filliing thickness and increases with the increase of the strength of the filling material.
\end{abstract}

\section{Keywords}

Filled rock joint; Static compression; Dynamic impact; Mechanical properties; Joint thickness

\section{Graphical Abstract}
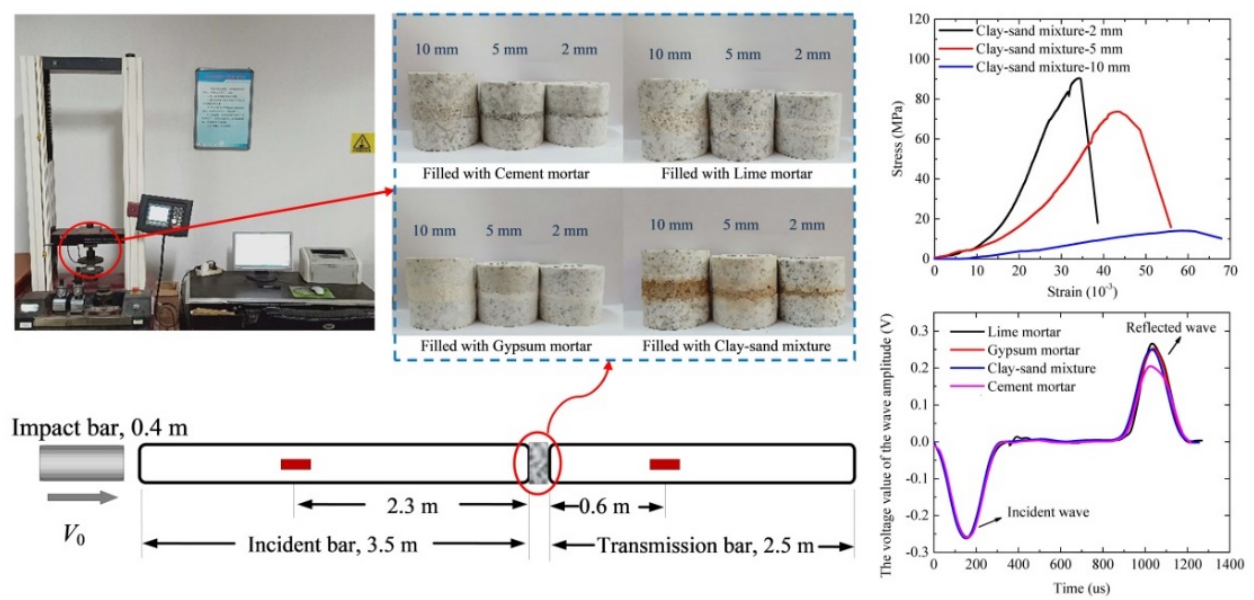


\section{INTRODUCTION}

Rock joint is the most extensive geological structure in the natural rock mass. Usually, the existence of joints will naturally divide the rock mass into a kind of discontinuous, non-uniform and anisotropic natural geological body, which significantly affects the physical and mechanical properties and the engineering qualities of the rock mass (Barton, 1973; Bandis et al, 1983). However, joints in rock mass often contain fillings. The low strength and large deformation of the fillings will change the mechanical behavior of the joint and the strength of the whole rock mass, increasing the instability of engineering rock mass. Study of the mechanical properties of filled rock joints is crucial to evaluate the stability and damage of rock structures, such as underground caverns, rock slopes and foundations under engineering loads.

So far, there have been many studies on the mechanical properties of joints. For example, some researchers (Malama and Kulatilake, 2003; Zhou et al., 2013; Yang et al., 2014, 2016; Liu and Zhang, 2015; Tian and Han, 2017) have studied the static uniaxial compression behavior of the rock samples with a single fracture, two intersecting joints or a parallel of non-persistent fissures, and have obtained the compression strength and deformation characteristics of these jointed rock samples. Many researches (e.g. Papaliangas et al., 1993; Zhao, 1997a, b; Li et al., 2006; Singh et al., 2011; Atapour and Moosavi, 2013, 2014; Jahanian and Sadaghiani, 2014) have been focused on the shear characteristics of joints. These results show that the shear mechanical properties of joints are related not only to the roughness of joint surface, joint size, rock strength and other natural properties, but also to the shear rate and the normal pressure. Studies on dynamic properties of joints are mainly carried out by the SHPB device. For example, researches (e.g., Zhang et al., 2013; Chen et al., 2014; Li et al., 2017; Wu et al., 2019) studied the influences of the factors such as joint roughness, contact area ratios of joint and impact loads on dynamic impact properties of joints based on SHPB test system. Above all, the mechanical properties of joints are mainly studied by axial compression, shear and dynamic impact. In addition, more researches are mainly focused on unfilled joints and fissure-containing joints, but relatively few experimental studies are made on the filled joints.

Compared with unfilled rock joints, the mechanical properties of filled joints are more complicated due to more affecting factors. The study of mechanical properties of filled joints has attracted extensive attention in the field of rock mechanics and engineering. At present, some studies of compression characteristics of filled rock joints are conducted mainly in the aspects of axial compression and dynamic impact. For example, Zhang et al. (2012) studied the strength characteristics and damage degree of the rock samples containing filled fracture through uniaxial compression. By comparing the strength and failure characteristics of intact rock and filled jointed rock under uniaxial compression, Yu et al. (2016) found that the mechanical parameters of joints are closely related to the structural distribution of the joints. Liu et al. (2014) studied the size effect on mechanical properties of filled joints through uniaxial compression and shear tests of filled cylindrical jointed rock samples with different height-diameter ratios.

For dynamic compression properties of the filled rock joints, Li and Ma (2009) carried out a systematic study on the artificial joints filled with sand through the improved SHPB test device in which the input and output bars are made of granite. The results show that the thickness and moisture content of the filling sand have great influence on the dynamic mechanical properties of the joint. Li et al. (2019) used SHPB test system to conduct uniaxial impact tests on granite samples containing artificial joints, and studied the influence of joint matching coefficient (JMC) on the quality factors of rock samples. In addition, considering factors such as joint distribution Angle, joint contact, joint number, joint spacing and length-diameter ratio of specimens, some researchers (e.g., Wu et al., 2013, 2014; Wu and Zhao, 2015; Liu and Su, 2016; Amalokwu et al., 2016) conducted dynamic impact compression tests on different types of rock joints and obtained the dynamic mechanical properties of the samples. The researches indicate that the dynamic strength as well as the failure mode of filled jointed rock is closely related to the joint structure form.

To sum up, some experimental studies have been carried out on the compression mechanical properties of filled rock joints, in which most of them focus on static or dynamic analysis, unilaterally. There are few comparative analyses of filled rock joints under static compression and dynamic impact at the same time. Moreover, there are relatively few experimental studies in which both filling materials and filling thickness factors are considered simultaneously. Accordingly, in this paper, the static mechanical properties and the dynamic behavior of filled rock joints are investigated by universal testing machine and SHPB device, respectively. In the study, both the characteristics of filling material and filling thickness of joint are considered because the two factors have a great influence on the mechanical properties of the jointed rock. Considering that it is difficult to sample the natural rock joints with specific structure, series of artificial filled jointed rock specimens with different fillings and joint thicknesses are prepared and tested in this paper. Through the static compression and dynamic impact tests, the strength characteristics, deformation characteristics, wave propagation characteristics and energy dissipation of the specimens are studied and analyzed. 


\section{SPECIMEN PREPARATION AND TEST PROCEDURE}

\subsection{Test Method}

Firstly, the artificial rock specimens filled with different filling materials and different filling thickness are prepared. Secondly, the static uniaxial compression tests are carried out by universal testing machine and then the compression properties of the filled jointed rock specimens are obtained. Then, based on stress wave propagation theory, using SHPB test device, the one-dimensional impact compression tests on P-wave propagation across filled rock joints are systematically carried out. Considering the influence of filling thickness and filling material properties, the dynamic compression mechanical properties of filled rock joints are obtained by analyzing the incident and transmitted waves across the filled rock joints. Finally, the static and dynamic compression test results are taken into account to obtain the dynamic mechanical characteristics under the influence of joint fillings properties, the filling thickness and other factors.

\subsection{Specimen Preparation}

Because the joint structure of rock specimens sampled in the field is not easy to identify, it cannot used for the single factor analysis of jointed rock mass. Therefore, in this experiment, similar materials are used to produce the artificial filled jointed rock specimens, which have the similar properties to the real jointed rocks. Through the static compression and SHPB dynamic impact tests, artificial jointed rock specimens are tested and then the mechanical properties of the filled joints are analyzed.

Granite materials with good texture from the same origin are selected and processed into cylindrical specimens with a diameter of $50 \mathrm{~mm}$ and a height of $25 \mathrm{~mm}$. One end face of the cylindrical granite blocks are polished and grooved regularly to make the surface roughness basically consistent. The filling material is intermingled between two granite blocks and in contact with the rough surfaces to constitute the filled jointed rock specimen, as shown in Fig. 1. In the actual rock mass, the physical and mechanical properties (such as density, strength, elastic modulus, wave velocity, etc.) of the joint fillings are generally between the rock besides the joint and the common clay. Therefore, similar materials including clay, sand, lime, gypsum, cement and so on are used in the tests for combined configuration, and mixed fillings with different properties were obtained. The four kinds of the fillings used in the middle of the specimens are the cement mortar, the gypsum mortar, the lime mortar and the mud-sand mixture, respectively. In the process of specimen making, the compactness of filling materials in the filling gaps should be controlled to ensure the consistency of similar specimens. In order to better simulate different types of the filled joints, the thickness of the filling material for fixed curing is $2 \mathrm{~mm}, 5 \mathrm{~mm}$ and $10 \mathrm{~mm}$, respectively. As rock is a kind of complex material, it is easily affected by various factors. In order to improve the reliability of the experiments, three specimens as a group are repeated in each test.

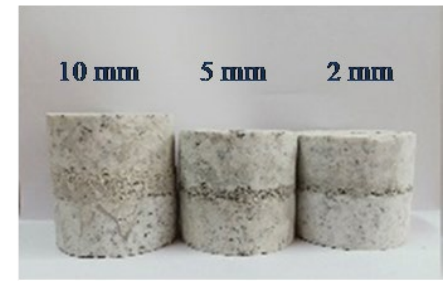

Filled with Cement mortar

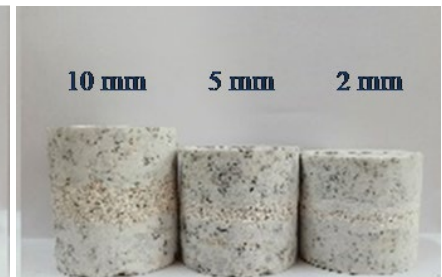

Filled with Lime mortar

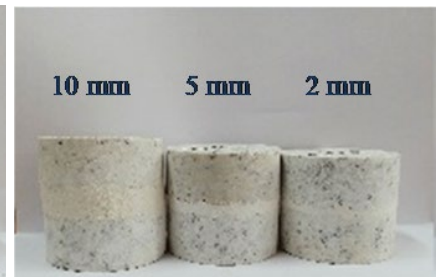

Filled with Gypsum mortar

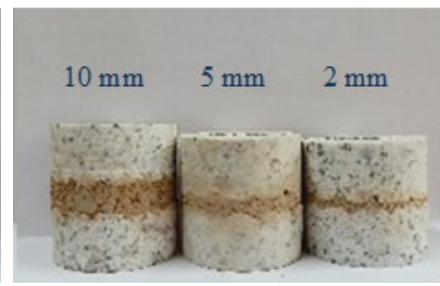

Filled with Clay-sand mixture

Figure 1: Filled jointed rock specimens

As shown in Fig. 1, the artificial filled jointed rock specimens are divided into four groups according to the type of filling materials, each of which is divided into three groups based on thickness. The physical and mechanical parameters of rock and filling materials measured under the same test conditions are shown in Table 1. It should be noted that the wave velocity in each filling material and granite is measured by RSM-SY5 acoustic velocity instrument developed by Institute of Rock and Soil Mechanics, Chinese Academy of Sciences. The schematic diagram of the wave velocity test is shown in Figure 2. During the measurement, the measured materials are made into a cylindrical test sample with a diameter of $50 \mathrm{~mm}$ and a height of $50 \mathrm{~mm}$. The wave velocity tests for rock and filling materials are carried out respectively. As shown in Fig.2, a transmitting probe and a receiving probe are placed at each end of the sample respectively. The transmitting probe sends out a high-voltage pulse signal at time $t_{1}$, which is received by the receiving 
probe at time $t_{2}$ after passing through the specimen. According to the wave propagation time, $\Delta t$, and the length of the specimen, $L$, the average wave velocity of the measured sample, $c_{p}$, can be calculated as:

$$
c_{p}=\frac{L}{\Delta t}=\frac{L}{t_{1}-t_{2}}
$$

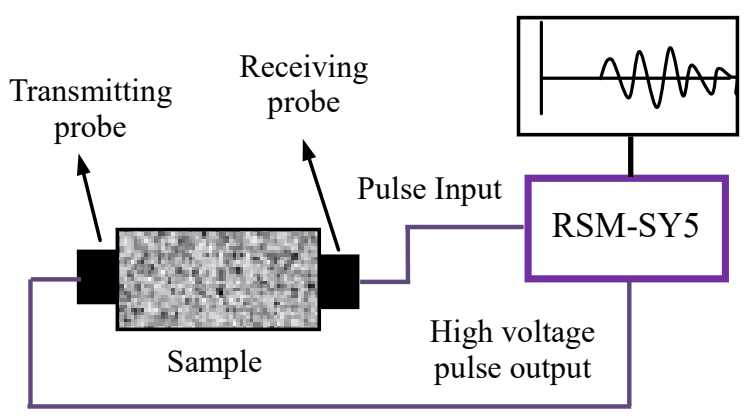

Figure 2: Schematic diagram of wave velocity measurement for rock and filling materials

It can be seen from Table 1 that the physical and mechanical parameters of the configured fillings are all smaller than the corresponding values of the rocks on both side of the joint, and there are obvious differences. Therefore, the properties of the four filling materials in this paper are similar to those of the natural fillings in rock mass, which are representative to some extent.

Table 1 Physical and mechanical Properties of the rock and the joint filling materials

\begin{tabular}{|c|c|c|c|c|c|c|}
\hline Materials & \multicolumn{2}{|c|}{ Mix proportion } & $\begin{array}{l}\text { Density } \\
\left(\mathrm{kg} / \mathrm{m}^{3}\right)\end{array}$ & $\begin{array}{c}\text { Strength } \\
\text { (MPa) }\end{array}$ & $\begin{array}{c}\text { Elasticity } \\
\text { modulus (GPa) }\end{array}$ & $\begin{array}{l}\text { Wave velocity } \\
(\mathrm{m} / \mathrm{s})\end{array}$ \\
\hline Cement mortar & Cement: Water: Sand & $1: 0.5: 2$ & 1912 & 35.7 & 32 & 2381 \\
\hline Gypsum slurry & Water: Gypsum & 1: 3 & 1400 & 2.27 & 1.0 & 1042 \\
\hline Lime mortar & Water: Lime: Sand & 1:1:3 & 1593 & 1.12 & 1.6 & 370 \\
\hline Clay-sand mixture & Water: Clay: Sand & $1: 2.67: 2.67$ & 1631 & 2.61 & 2.3 & 1429 \\
\hline The rocks & Granite & - & 2430 & 67 & 57 & 3368 \\
\hline
\end{tabular}

\subsection{The Test Procedure}

The static compression tests are carried out by the WAW3030 microcomputer control universal testing machine, as shown in Fig. 3(a). The test force loading control is adopted during the test, and the loading rate is $50 \mathrm{~N} / \mathrm{s}$. The dynamic impact tests are carried out by the Split Hopkinson Bar (SHPB) device, as shown in Fig. 3(b). As shown in Fig. 3(c), the device includes four pressure bars, i.e., the impact bar, the incident bar, the transmission bar and the absorption bar. The four bars are all made of steel with a diameter of $50 \mathrm{~mm}$. The elastic modulus of the pressure bar is $210 \mathrm{GPa}$, the density is $7800 \mathrm{~kg} / \mathrm{m}^{3}$, the theoretical velocity of elastic longitudinal wave is $5200 \mathrm{~m} / \mathrm{s}$, and the measured velocity is $5227 \mathrm{~m} / \mathrm{s}$. The length of the impact bar is $0.4 \mathrm{~m}$, the length of the incident bar is $3.5 \mathrm{~m}$, the length of the transmission bar is $2.5 \mathrm{~m}$, and the length of the absorption bar is $1.5 \mathrm{~m}$.

In the test, the strain gauges are applied symmetrically to eliminate the error caused by the bending deformation of the elastic bar during the impact. At the same time, in order to prevent the superposition of the waves, the strain gauges are pasted on the incident bar $2300 \mathrm{~mm}$ away from the contact surface of the specimen, and on the transmission bar $600 \mathrm{~mm}$ away from the contact surface of the specimen. As shown in figure 3c, the strain gauge is connected to the dynamic strain acquisition instrument.The stress wave signals collected in the strain acquisition instrument are displayed on the oscilloscope after the amplification gain of 1000 times and then stored in the connected computer. In this study, the sampling frequency of the strain acquisition instrument is set to $1 \mathrm{MHz}$. The chosed sampling time is $16.38 \mathrm{~ms}$. Since the bridge voltage of the junction box is adopted as $2 \mathrm{~V}$, a single strain gauge will produce $1 \mu \varepsilon$ when the output voltage is $1 \mathrm{mV}$.

As the jointed rock mass belongs to brittle material, and its failure strain is very small. In order to satisfy the stress uniformity and eliminate the diffusion effect of stress wave propagation, and make the incident waveform smooth, the 
rubber shaper is used as a pulse shaper during the test. To ensure the accuracy and reliability of the test results, each set of tests was repeated 3 times. The specific contents and methods are shown in Table 2.

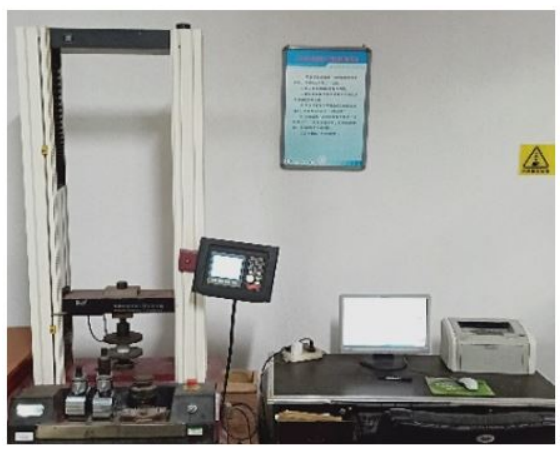

(a)

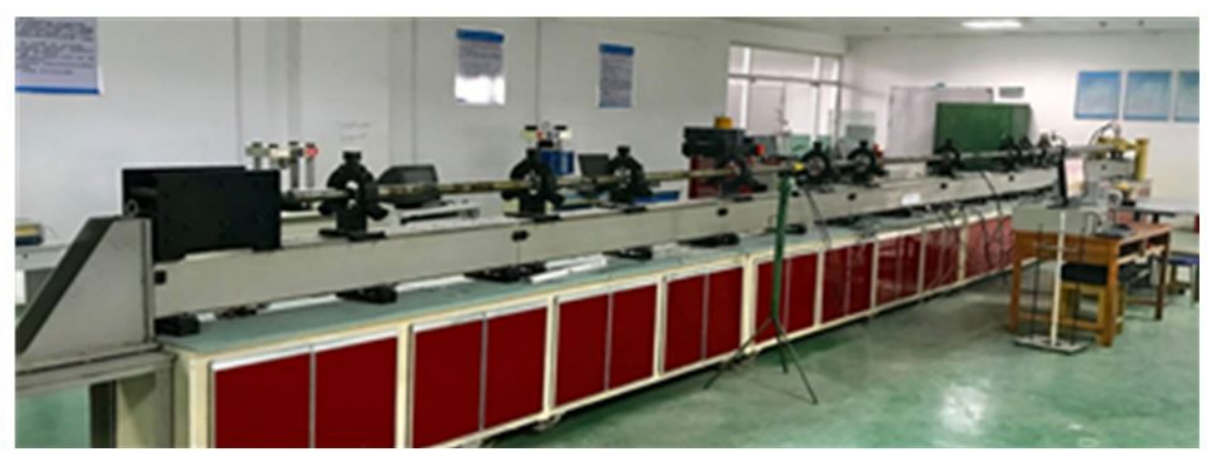

(b)

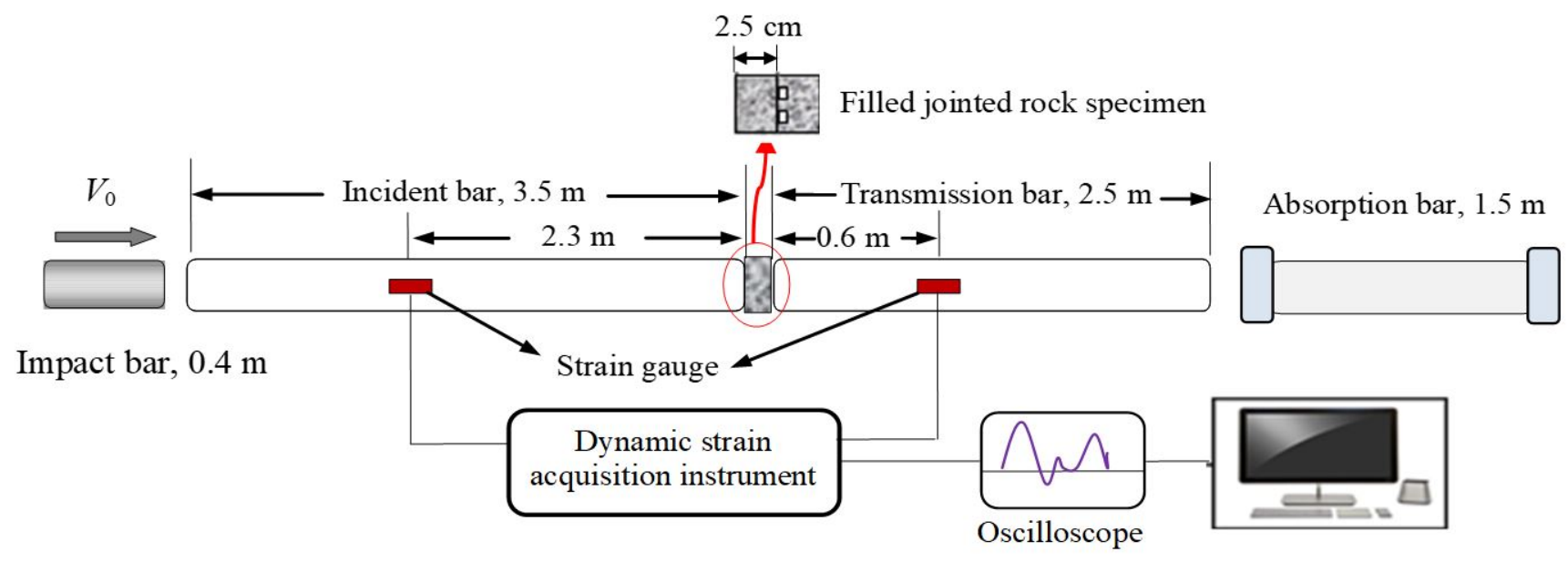

(c)

Figure 3: The testing instruments. (a) The WAW3030 microcomputer control universal testing machine; (b) The picture of Split Hopkinson Bar (SHPB) device; (c) The Schematic diagram of SHPB device.

Table 2 The testing content and methods

\begin{tabular}{cccccc}
\hline Test content & Filling material & Filling thickness & Test device & Loading mode & Intensity of loading \\
\hline $\begin{array}{c}\text { Static uniaxial } \\
\text { compression }\end{array}$ & Cement mortar & $2 \mathrm{~mm}$ & WAW3030 & Test force loading \\
& Gypsum mortar & $5 \mathrm{~mm}$ & $\begin{array}{c}\text { microcomputer control } \\
\text { universal testing } \\
\text { machine }\end{array}$ & \\
& & $10 \mathrm{~mm}$ & Split Hopkinson Bar & Compressed gas & $0.2 \mathrm{MPa}$ \\
$\begin{array}{c}\text { 1-D dynamic } \\
\text { impact }\end{array}$ & Lime mortar & & (SHPB) device & pressure control & \\
\hline
\end{tabular}

\section{THE STATIC COMPRESSION RESULTS AND ANALYSIS}

In the static compression process, the loading force-time history $(F-t)$ and the loading displacement-time history $(\Delta L-t)$ of the samples is recorded. In the end, the corresponding relation curves can be obtained, in which the loading displacement, $\Delta L$, is the compression deformation of the jointed rock sample. As we all know, stress and strain are respectively defined as $\sigma=F / s$ and $\varepsilon=\Delta L / L$, where $S$ and $L$ are the cross-sectional area and length of the specimen respectively. Accordingly, the relationship between stress and time $(\sigma-t)$ as well as the relationship between strain and time $(\varepsilon-t)$ can be derived. Then, the relationships between stress and strain $(\sigma-\varepsilon)$ can be obtained by eliminating time $t$. Fig. 4 shows the stress-strain curves of the artificial filled joints with four different filling materials and three corresponding filling thicknesses.

It can be seen from Fig. 4 that the uniaxial compression stress-strain curves of the rock joints specimens with same filling material but different filling thicknesses have a consistent change trend. With the change of filling thickness, the 
peak stress and strain change accordingly. By comparing the stress-strain curves of the jointed rock specimens with the same thickness but different filling materials, it can be seen that the strength and deformation characteristics of the filled joints are also greatly affected by the filling materials.
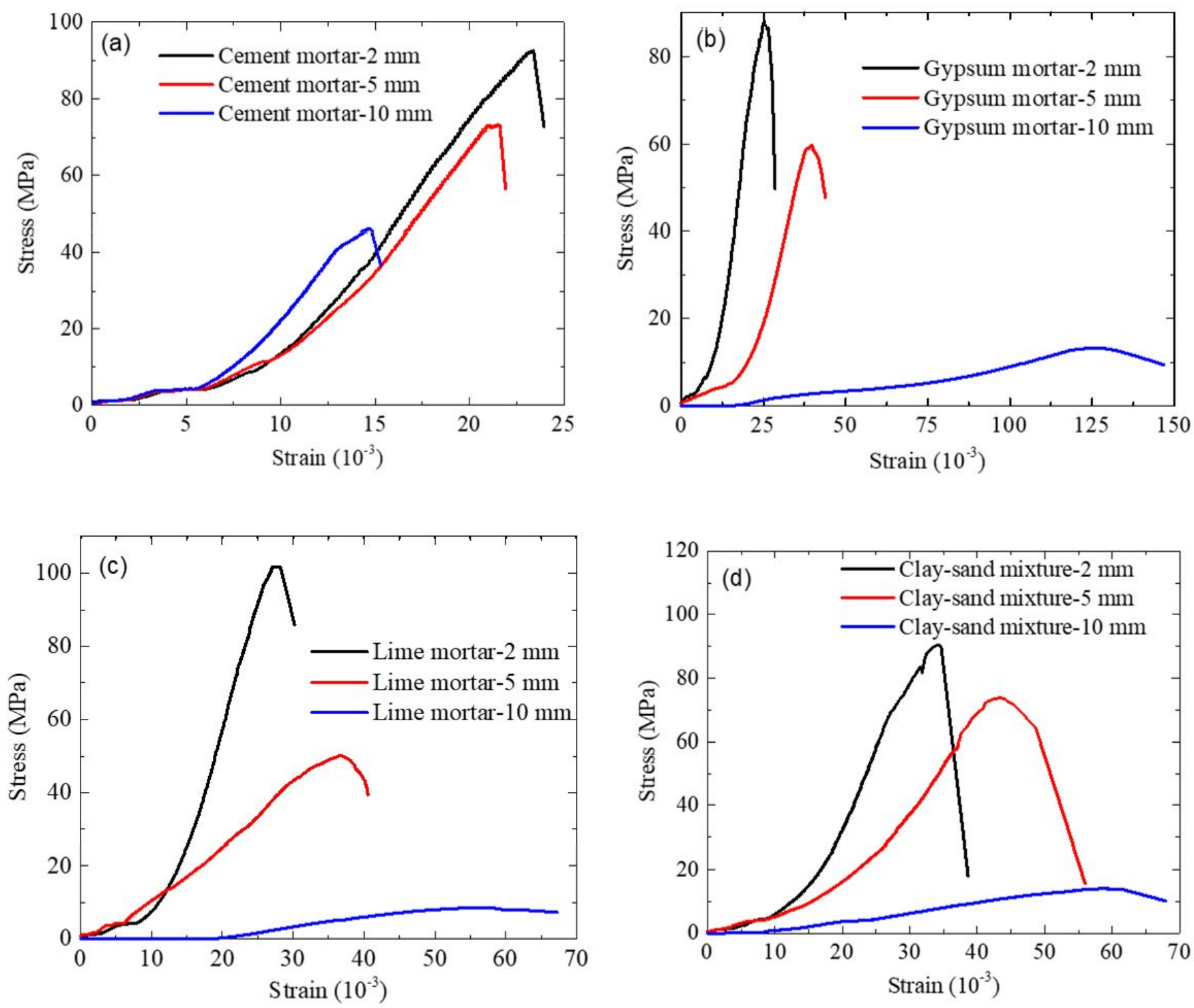

Figure 4: The Static compressive stress-strain curves of filled joints. (a) The joints filled with cement mortar; (b) The joints filled with gypsum mortar; (c) The joints filled with lime mortar; (d) The joints filled with clay-sand mixture

For the joints filled with the cement mortar, the increase of filling thickness has little effect on the elastic modulus of the specimens. As a result, the slopes of the three curves are basically the same. The effect of filling thickness on peak stress and corresponding strain is obvious. The curves in Fig. 4(a) shows that the peak stress and the corresponding strain of sample decrease as the filling thickness increases.

For the jointed rock specimens filled with the other three filling materials, the thickness of the filling material has an obvious influence on the peak stress, strain and elastic modulus. With the increasing of joint filling thickness, the elastic modulus decreases, the peak stress decreases while the corresponding strain increases under uniaxial compression. In particular, the average peak stress when the filling thickness is $10 \mathrm{~mm}$ decreases to less than $20 \%$ of the peak stress of the samples with $2 \mathrm{~mm}$ filling thickness while the corresponding strain is 2-5 times of that when the filling thickness is $2 \mathrm{~mm}$. The main reason is that both the strength and elastic modulus of the three filling materials are smaller than those of the granite as well as the cement mixture. Before the filled jointed rock specimen reaches the peak stress, the filling layer has been damaged. The rocks on both sides of the joint fail to give full play to the strength of the jointed rock specimen. As a result, the greater the filling thickness, the greater the peak strain. 
The static compression mechanical characteristics of the filled joints are analyzed below in this section from the failure mode, the strength and the deformation.

\subsection{Analysis of the Failure Mode}

The failure process and failure mode of the filled joints under static uniaxial compression are shown in Fig. 5. It can be seen that the failure of specimen containing filled joints occurs first in the joint fillings under uniaxial compression. With the axial pressure increasing, the filled joint interface changes from scaling failure and wrinkling to brittle fracture. As the axial pressure continues, the cracks gradually develop inward. At the same time, the filled joint is continuously compressed to yield. Further loading until the fillings cannot be compressed, the rocks on both sides of the joint begin to be compressed to produce visible deformation and crack until failure. It can be observed from the failure shape of the jointed specimens that the lateral failure of filled joint is the most serious. The failure surfaces of the rock specimens mainly include the local shear failure surfaces and the rupture surfaces along the axis. Accordingly, the failure modes of the filled jointed rock are mainly the shear failure and the splitting failure.

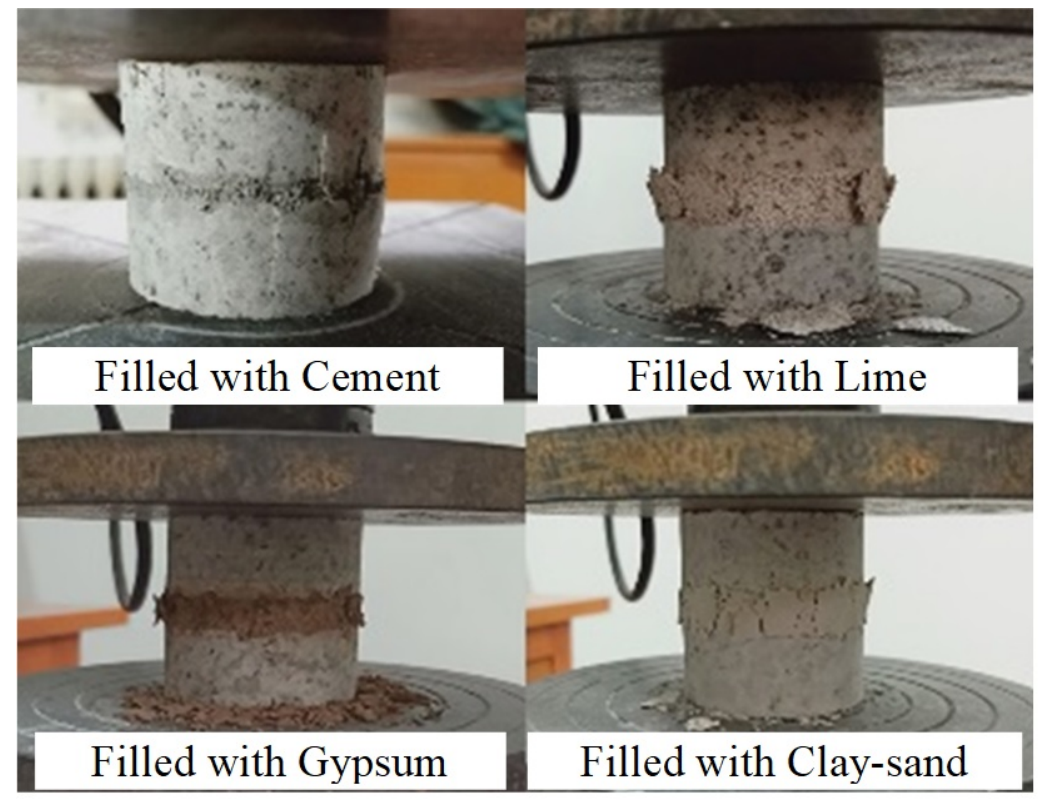

(a) Failure process of the specimens

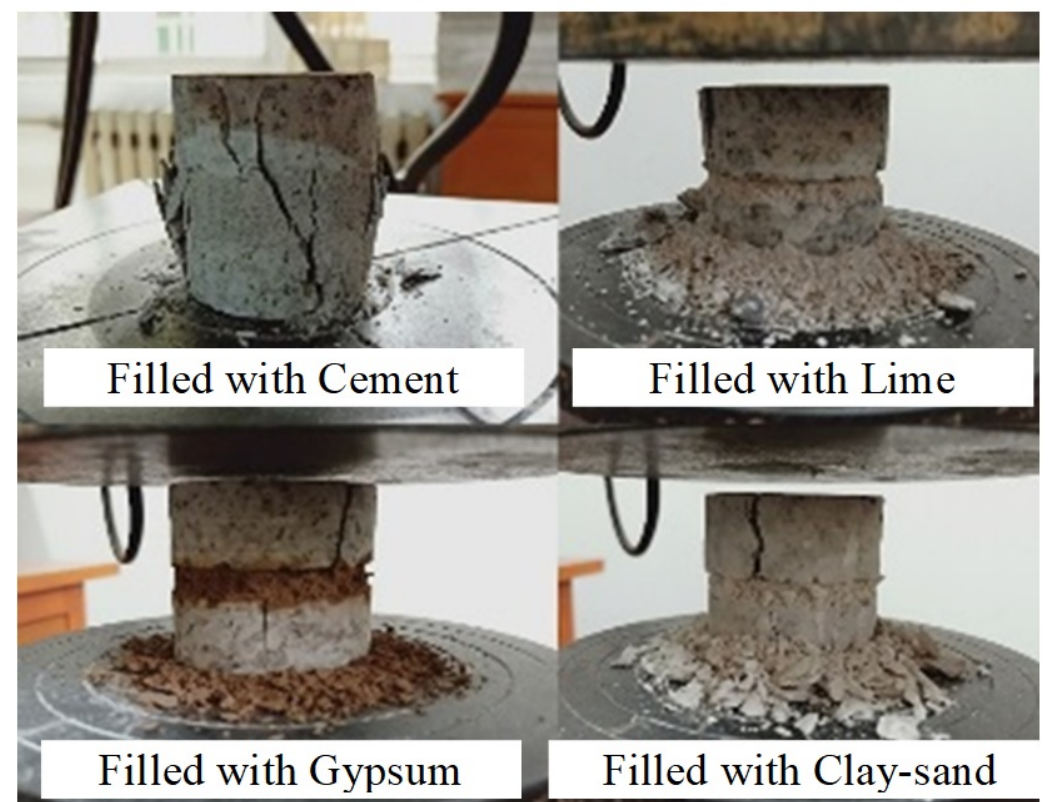

(b) Final failure form of the specimens.

Figure 5: Failure process and final failure form of filled joints under uniaxial compression 
Combined with the stress-strain curves of the filled jointed rock under uniaxial compression, it can be seen that the whole compression process can be roughly divided into three kinds of typical stages, as follows:

Stage 1: The joint compression stage. At this stage, the stress does not increase but the strain gradually increases. The strain of the rock on either side of the joint is supposed to be not large at this stage. The main manifestation of this stage is that the middle filling layer is gradually compressed and the strain of the joint increases linearly.

Stage 2: The joint failure stage. At this stage, the joints are continuously compressed to be damaged, resulting in a certain plastic deformation. As the axial pressure continues, the deformation of the filling layer is no longer linear elastic. Meanwhile, the normal stiffness and compression modulus of the middle filling layer are increasing, which are finally close to those of the rock on both sides of the joint.

Stage 3: The rock compression stage. In this stage, the middle joint thickness reaches the minimum, and the filling layer is difficult to continue be compressed. It supposed that the main change in this stage is that the rock is compressed, and the strain of the rock increases continuously until the failure. The ultimate failure is manifested as compression-shear or splitting failure of the rock.

\subsection{Influence of Joint Filling Thickness on the Strength}

With the change of thickness of the joint fillings, the strength of each jointed rocks filled with the four different filling materials shows a consistent rule. Taking the joints filled with the clay-sand mixture as an example, when the joint thickness are respectively $2 \mathrm{~mm}, 5 \mathrm{~mm}, 10 \mathrm{~mm}$, the corresponding peak stress are 90.4 MPa, 73.7 MPa, 13.8 MPa, while the corresponding peak strain are $0.034,0.043,0.061$, respectively. When the joint filling thickness changes from $2 \mathrm{~mm}$ to $5 \mathrm{~mm}$, the peak strength will decrease by $18.4 \%$ while the peak strain will increase by $26.5 \%$. When the joint filling thickness changes from $5 \mathrm{~mm}$ to $10 \mathrm{~mm}$, the strength will decrease by $81.3 \%$ while the peak strain will increase by $41.9 \%$. It can be seen obviously that with the increase of joint filling thickness, the peak strength the jointed rock specimen filled with the the clay-sand mixture decreases gradually while the peak strain increase. Similarly, the joints filled with the other three filling materials also follow the same pattern. Thus, the joint filling thickness is negatively correlated with the compression strength of the filled jointed rock while positively correlated with deformation.

\subsection{Influence of the Filling Materials on the Strength}

Under the same test conditions, the strength of the four filling materials is measured, as shown in Table 1. The sequence from high to low is: cement mortar, clay-sand mixture, gypsum mortar and lime mortar. When the joint thickness is relatively larger (i.e., $10 \mathrm{~mm}$ ), the sequence of strength remains the same with that of specimen thickness. As the strength of the filling materials decreases, the strength of the jointed rock accordingly decreases. In another word, the compression strength of the filled jointed rock specimen depends on the strength of the fillings. What's more, when the thickness of the filling material exceeds a certain range, the strength value of the filled joint is mainly determined by that of the filling material. When the filling thickness is small, the strength of filled joint is relatively high. The possible reason is that the joint surface is not smooth, which causes some clay, sand and other fillings to fill the void between the original joint surfaces during the joint formation process. However, the joint thickness is too small to form a weak layer. Thus, the contact area between the rock blocks on both sides of the joint is strengthened, increasing the strength of the joint at last.

Because the strength of joint fillings is lower than that of rocks on both sides, it can be seen from Fig. 5 that the weak structural joint surface first begins to fail when failure of the filled jointed rock occurs. Moreover, for the joints filled with different materials but with a same thickness, the failure modes are different due to the different strength of filling materials. When the strength of the filling material is relatively high (e.g., cement mortar), the failure mode is the failure of the contact surface between the filling and the rocks. When the strength of the filling is low (e.g., lime mortar, gypsum mortar or clay-sand mixture), the failure mode is the failure of the filling itself.

\section{THE DYNAMIC IMPACT COMPRESSION RESULTS AND ANALYSIS}

The one-dimensional impact compression tests of the artificial filled jointed rock specimens are carried out by using SHPB device. Since the impact velocity of the test device cannot be accurately measured every time, approximately equal incident wave amplitudes can be obtained by controlling the pressure value of the compressed gas $(0.2 \mathrm{MPa})$. In order to ensure the credibility of the test results, each test for a set of specimens is carried out repeatedly three times. Based on the experimental results, the dynamic properties of the filled joints are analyzed and studied from the aspects of the strength of joint, wave propagation characteristics and the energy transfer. 


\subsection{Analysis of the Filled Joints Strength under Impact Compression}

When the stress wave generated by the impact compression propagates in the bars, the strain gauges pasted on the incident bar and the transmission bar deform along with the elastic bars. Meanwhile, the deformation of the strain gauges causes the change of their own resistance, which will cause the change of the voltage of the measuring circuit bridge box, accordingly. Thus, the incident, reflected and transmitted waves can be transformed into the corresponding incident, reflection and transmission voltage signals which are recorded and stored by the ultrahigh dynamic strain acquisition instrument. Then, the incident strain, $\varepsilon_{i}$, reflected strain, $\varepsilon_{r}$, and transmitted strain, $\varepsilon_{t}$, can be obtained by the conversion relation between strain and voltage which is determined by the strain gauge parameters. According to the three-wave method (Song and Hu, 2005; Wang and Shang, 2014), the average strain $\varepsilon(t)$ and stress $\sigma(t)$ of the jointed rock sample can be calculated as follows:

$$
\begin{aligned}
& \varepsilon(\mathrm{t})=\frac{C}{L} \int_{0}^{t}\left(\varepsilon_{i}-\varepsilon_{r}-\varepsilon_{t}\right) d_{t} \\
& \sigma(\mathrm{t})=\frac{A E}{2 S}\left(\varepsilon_{i}+\varepsilon_{r}+\varepsilon_{t}\right)
\end{aligned}
$$

where $A$ is the cross-sectional area of the compression bar, $E$ is the elastic modulus of the compression bar, and $C$ is the wave velocity in the bar. The dynamic stress-strain relationship of the filled rock samples under impact compression can be obtained after the time $t$ is eliminated by simultaneous equations 4 and 5 . Then, the corresponding dynamic stress-strain curves are obtained accordingly, as shown in Fig. 6.

It can be seen from Fig. 6 that the peak stress of joints with any filling decreases with the increase of joint filling thickness. That is to say, the dynamic compression strength decreases with the increase of joint thickness, indicating that the dynamic compression strength of filled joints is highly correlated with the strength of intermediate filling.
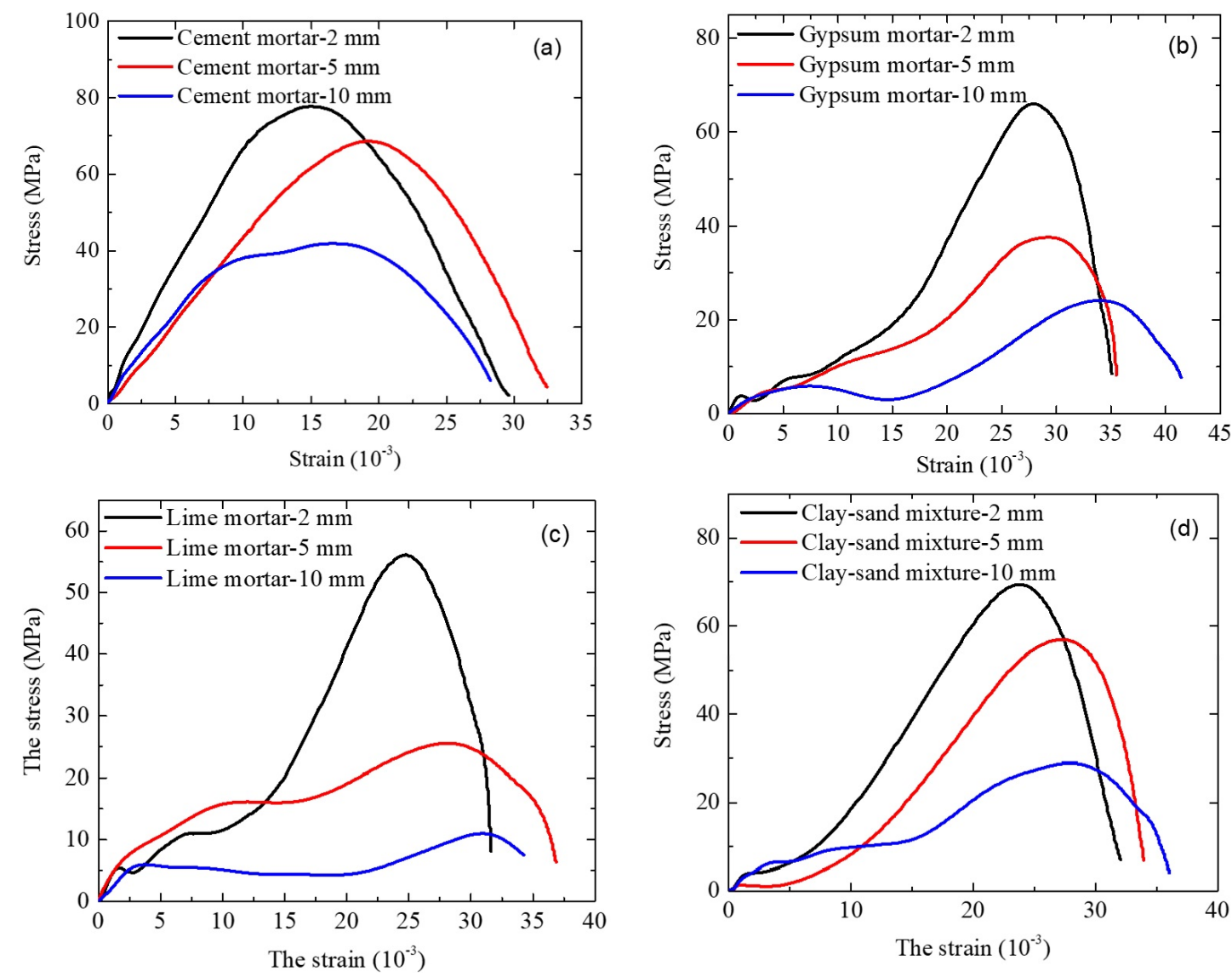

Figure 6: The dynamic compression stress-strain curves of filled joints. (a) The joints filled with cement mortar; (b) The joints filled with gypsum mortar; (c) The joints filled with lime mortar; (d) The joints filled with clay-sand mixture. 
Table 3 Dynamic peak stress and strain under impact compression

\begin{tabular}{ccccccc}
\hline Filled joint & \multicolumn{2}{c}{$\mathbf{2 m m}$} & \multicolumn{3}{c}{$\mathbf{5 m m}$} & \multicolumn{1}{c}{$\mathbf{1 0 m m}$} \\
\cline { 2 - 7 } & $\boldsymbol{\sigma}_{\max }$ & $\boldsymbol{\varepsilon}_{\max }$ & $\boldsymbol{\sigma}_{\max }$ & $\boldsymbol{\varepsilon}_{\max }$ & $\boldsymbol{\sigma}_{\max }$ & $\boldsymbol{\varepsilon}_{\max }$ \\
\hline Cement mortar & 77.7 & 0.015 & 68.6 & 0.019 & 41.9 & 0.169 \\
Clay-sand mixture & 69.4 & 0.024 & 56.9 & 0.025 & 29.0 & 0.028 \\
Gypsum slurry & 66.0 & 0.028 & 37.6 & 0.029 & 24.1 & 0.034 \\
Lime mortar & 56.1 & 0.025 & 25.5 & 0.028 & 11.0 & 0.031 \\
\hline
\end{tabular}

However, not all the peak strains of the filled joints increase monotonically with the increase of joint thickness. It is related to the filling material properties. For the joints filled with the three relatively soft fillings, i.e., clay-sand mixture, gypsum mortar and lime mortar, the peak strain of each specimen increases with the increase of joint filling thickness. It indicates that the deformation of joints with softer fillings increase with the increasing of joint thickness under impact compression. Table 3 shows the dynamic peak stress and the strain of the filled joints under impact compression. For the joints filled with hard fillings (e.g., cement mortar), the peak strain of the joints is generally small. Moreover, when the joint thickness is $5 \mathrm{~mm}$, the strain value is maximized. It preliminarily indicates that the joint filling layer and the rocks on both sides of joint are bonded as a whole due to the high bonding strength of cement. Therefore, under impact loading, the deformation of the rock specimen filled with cement mortar is not obvious with the change of joint thickness but shows some brittle characteristics due to their high strength. However, for the above mentioned soft joints, the strain is relatively large and the deformation presents a certain plastic failure characteristic, among which the joint filled with gypsum is the most obvious.

\subsection{Wave Propagation Characteristics through the Filled Joints}

In the analysis of the influence of the joint thickness on the wave propagation characteristics, the case of the joints filled with clay-sand mixture is taken for example. Fig. 7 shows the incident wave, transmitted wave and reflected wave curves of the jointed rock specimens under one-dimensional impact. It can be seen from Fig. 7 that different joint thicknesses have different effects on transmission and reflection of stress waves. When the incident wave is the same, with the increase of joint thickness, the amplitude of the reflected wave gradually increases in a small range while the amplitude of the transmitted wave gradually decreases. It indicates that the filling material in the filled joint hinders the transmission of the stress wave. The thicker the joint filling is, the greater the amplitude attenuation of transmitted wave is, and the weaker the transmission capacity of stress wave is.
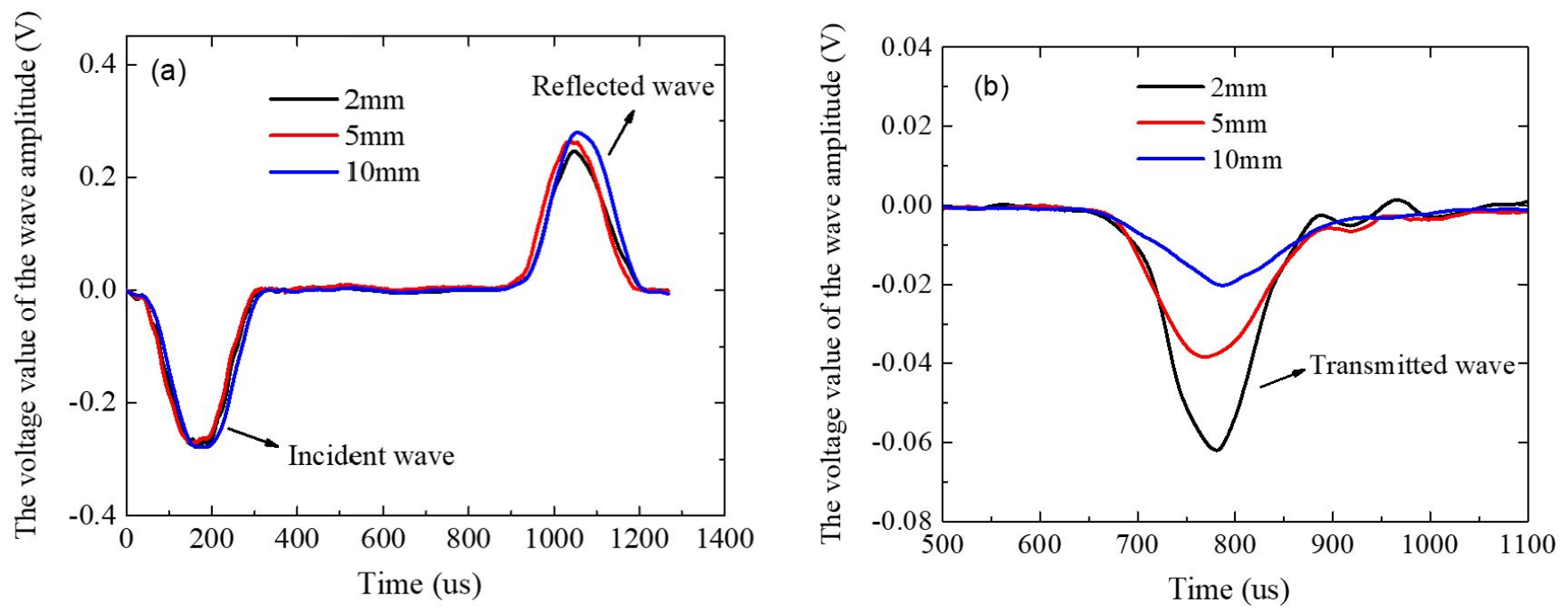

Figure 7: The waveform curves of the jointed rock specimens filled with clay-sand mixture under one-dimensional impact. (a) The incident wave and reflected wave; (b) The transmitted wave. 

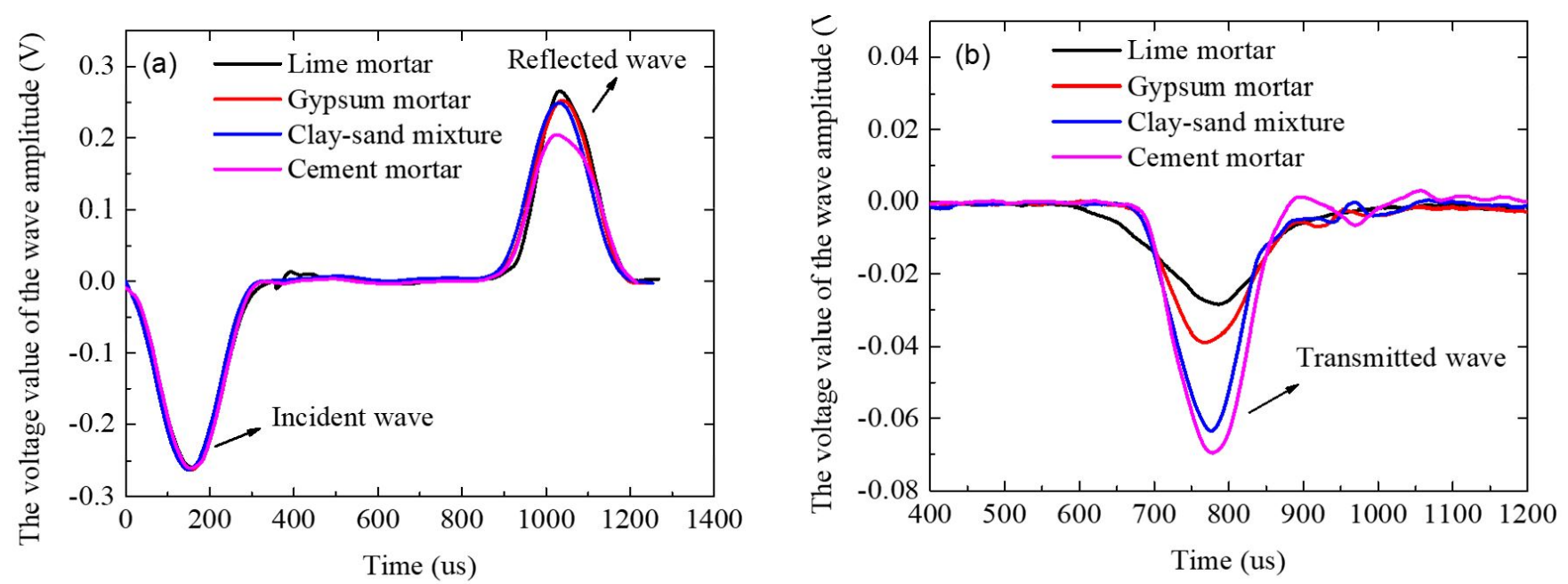

Figure 8: The waveform curves of the filled jointed rock specimens with a filling thickness of $5 \mathrm{~mm}$ under one-dimensional impact.

(a) The incident wave and reflected wave; (b) The transmitted wave.

When study the influence of joint filling materials properties, the test results of all filled jointed rock samples with a thickness of $5 \mathrm{~mm}$ are selected for analysis. The waveform curves are shown in Figure 8. As shown in the figure, the reflected wave amplitude of the soft fillings rock samples (e.g., clay-sand mixture, gypsum mortar and lime mortar) is slightly smaller than the incident wave amplitude, while the reflected wave amplitude of the hard fillings samples (e.g., cement mortar) attenuates to a certain extent. Combined with the strength relationship of filling materials (from high to low is: cement mortar, clay-sand mixture, gypsum mortar and lime mortar.), from Fig. 8(b), it shows that the amplitude of transmitted wave is positively correlated with the strength of jointed filling materials. The reflected wave amplitude of the joints containing hard materials is bigger than that of soft filling materials. It indicates that the hard filling materials have little influence on the transmission of stress waves while soft fillings have a certain influence on the stress wave transmission.

In conclusion, the reflected coefficient is not only related to the strength of the filling material, but also to the thickness of the filling layer. This conclusion is consistent with the theoretical study on the propagation of stress wave in the filled rock joint (Li et al., 2010). The mainly reason is that the change of the joint fillings can makes the wave impedance of the filled joint rock sample change. The wave impedance represents the stress which is necessary for the particle to produce unit vibration velocity when it is disturbed in rock. The greater the wave impedance, the greater the stress required to produce unit vibration velocity; on the contrary, the smaller the wave impedance, the smaller the stress required. It is defined as:

$z_{p}=\rho c_{p}$

where $\rho$ is the material density; $c_{p}$ is the wave velocity in the material, which can be measured by the acoustic velocity instrument as shown in Fig.2.

According to the one-dimensional elastic wave theory (Achenbach, 1973), when the wave in the incident rod propagates to the jointed rock sample, it satisfies the following equation:

$$
\frac{\sigma_{i}}{z_{p 1}}-\frac{\sigma_{r}}{z_{p 1}}=\frac{\sigma_{t}}{z_{p 2}}
$$

where $\sigma_{i}, \sigma_{r}$ and $\sigma_{t}$ are stress caused by incident wave, reflected wave and transmitted wave respectively; $z_{p 1}$ and $z_{p 2}$ are the wave impedance of the pressure bar and the wave impedance of rock sample respectively. In addition, according to the stress continuity condition:

$\sigma_{i}+\sigma_{r}=\sigma_{t}$

the reflected coefficient can be obtained by combining quation 5 and 6 , expressed as 
$R=\left|\frac{\sigma_{r}}{\sigma_{i}}\right|=\frac{z_{p 1}-z_{p 2}}{z_{p 1}+z_{p 2}}$

As shown in Figure 2, the jointed rock samples in this study are the combination of granite blocks and the filling layer. If the sample is regarded as a homogeneous material, the wave impedance of the sample can be expressed as $\overline{z_{p}}=\bar{\rho} \cdot \overline{c_{p}}$, where $\bar{\rho}$ is the average density of the jointed rock sample and $\overline{c_{p}}$ is the average wave velocity of the sample. According to table 1 , the smaller the strength of filling material is, the smaller the corresponding density and wave velocity are, leading to the decrease of the average impedance of rock sample. In adiition, the density and wave velocity of any filling material are smaller than those of granite. Thus, the thicker the filling layer of the jointed rock sample is, the smaller the average impedance is. It is obvious from Equation 7 that the transmitted coefficient $R$ increases as the average impedance of rock sample $\overline{z_{p}}$ decreases.

The above results can, at least qualitatively, depict the effects of the filling materials and the filling thickness on the reflection coefficient. However, it cannot reflect the increasing degree of the reflection coefficient caused by the decrease of the fiiling material strength or the increase of the filling thickness. Indeed, the jointed rock sample is not homogeneous material and contains two connection interfaces, in which the propagation process of stress wave is complicated. Therefore, it is difficult to conduct quantitative analysis by wave propagation theory.

\subsection{Analysis of the energy dissipation}

The rule about the filled rock joints on wave energy dissipation under impact compression is analyzed in this section. By the three-wave method, the incident strain, $\varepsilon_{i}$, reflected strain, $\varepsilon_{r}$, and transmitted strain, $\varepsilon_{t}$, can be obtained. On this basis, the incident energy, $E_{i}$, the reflected energy, $E_{r}$ and the transmitted energy, $E_{t}$, can be calculated according to the one-dimensional stress wave theory and law of conservation of energy. It can be expressed as:

$$
E_{m}=A \cdot E \cdot C \int_{0}^{t} \varepsilon_{m}^{2} d_{t}
$$

where $m$ is $i, r$ or $t$, represents incident wave, reflected wave and transmitted wave, respectively. Assuming that there is no energy dissipation during the stress wave propagation in the pressure bars, the energy dissipated on the jointed rock sample, $E_{s}$, can be calculated according to the law of energy conservation:

$$
E_{s}=E_{i}-E_{r}-E_{t}
$$

To eliminate the influence of incident amplitude fluctuation, the energy dissipation ratio, $E_{\mathrm{s}} / E_{\text {, }}$, is defined to analyze the influence of stress wave energy transfer in filled joints under impact compression. The calculated results based on the above Equation are shown in Table 4. Ignoring the energy loss in the stress wave propagation in the pressure bars, the majority of $E_{s}$ is mainly used for joint damage and failure, and the value of $E_{\mathrm{s}} / E_{i}$ reflects the degree of energy required for the filled joint failure. The influences of the joint thickness and the filling materials on the energy dissipation of the filled rock joints under impact compression are analyzed, as shown in Fig. 9.

\begin{tabular}{|c|c|c|c|c|c|}
\hline $\begin{array}{c}\text { Specimen Properties } \\
\text { (Filling material-Filling thickness) }\end{array}$ & $E_{i}(\mathrm{~J})$ & $E_{r}(\mathrm{~J})$ & $E_{t}(\mathrm{~J})$ & $E_{s}(\mathrm{~J})$ & $E_{s} / E_{i}$ \\
\hline Clay-sand mixture $-2 \mathrm{~mm}$ & 426.9 & 308.0 & 19.5 & 99.4 & $23.28 \%$ \\
\hline Clay-sand mixture $-5 \mathrm{~mm}$ & 497.1 & 419.8 & 16.0 & 61.3 & $12.33 \%$ \\
\hline Clay-sand mixture $-10 \mathrm{~mm}$ & 440.1 & 391.7 & 4.6 & 43.8 & $9.95 \%$ \\
\hline Gypsum mortar -2 mm & 450.4 & 351.6 & 15.3 & 83.5 & $18.54 \%$ \\
\hline Gypsum mortar -5 mm & 484.2 & 426.1 & 7.8 & 50.3 & $10.39 \%$ \\
\hline Gypsum mortar -10 mm & 462.7 & 451.5 & 3.3 & 8.0 & $1.73 \%$ \\
\hline Cement mortar $-2 \mathrm{~mm}$ & 440.4 & 289.5 & 26.5 & 124.4 & $28.25 \%$ \\
\hline Cement mortar $-5 \mathrm{~mm}$ & 460.2 & 309.6 & 21.0 & 129.6 & $28.16 \%$ \\
\hline Cement mortar $-10 \mathrm{~mm}$ & 442.1 & 356.5 & 8.5 & 77.1 & $17.44 \%$ \\
\hline Lime mortar $-2 \mathrm{~mm}$ & 486.7 & 388.2 & 15.6 & 82.9 & $17.04 \%$ \\
\hline Lime mortar $-5 \mathrm{~mm}$ & 471.2 & 423.2 & 4.9 & 43.1 & $9.15 \%$ \\
\hline Lime mortar $-10 \mathrm{~mm}$ & 459.5 & 455.4 & 1.9 & 2.2 & $0.48 \%$ \\
\hline
\end{tabular}

Table 4 Stress wave energy and energy consumption ratio of the joints under impact compression 

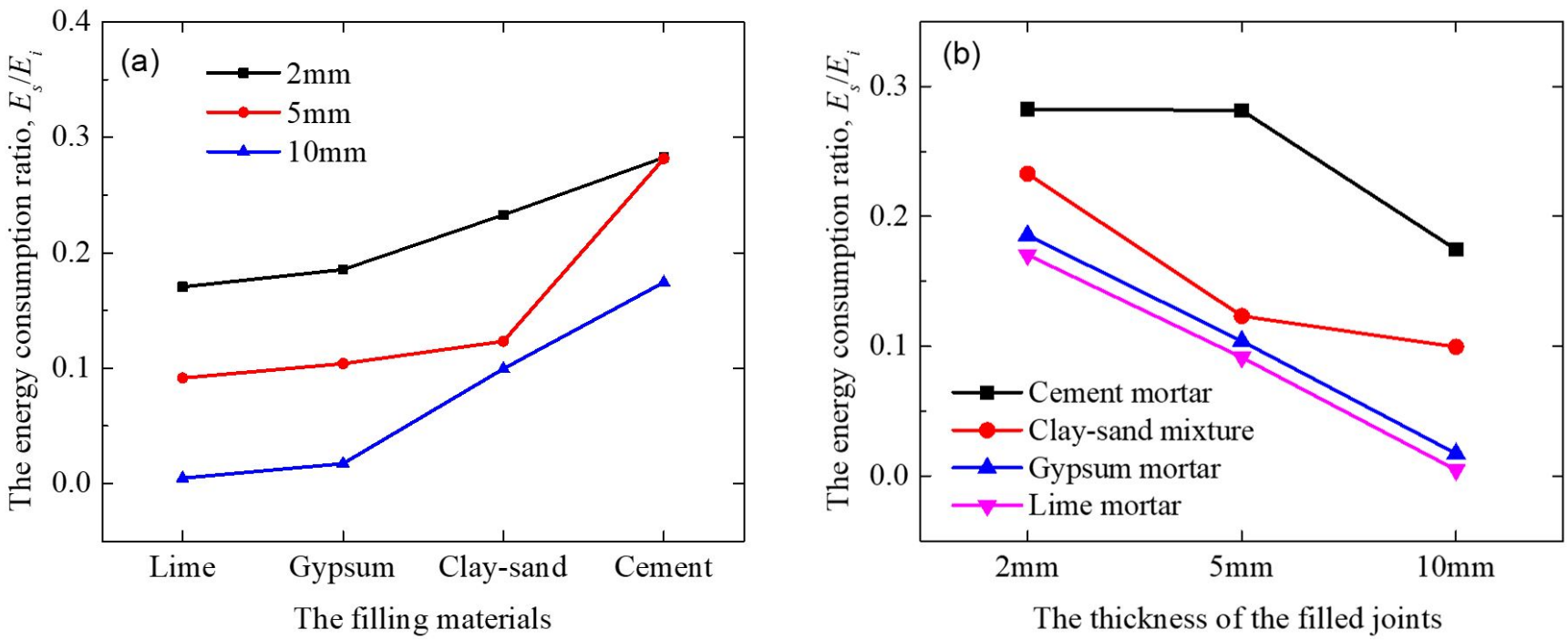

Figure 9: The energy consumption ratio of the filled joints under impact compression. (a) Relation between the energy consumption ratio and the joint filling material; (b) Relation between the energy consumption ratio and the joint filling thickness.

As can be seen from Fig. 9 (a), the energy dissipation ratio of the filled joints with the same filling thickness but different filling materials under impact compression is related to the strength of the filling materials. It shows that the energy dissipation ratio increases with the increasing of the filling material strength. It indicates that when damage and failure happen, the higher the strength of the filling material is, the higher the energy dissipation value of the joint needs under impact compression.

It can be seen from Fig. 9 (b) that the energy dissipation ratio decreases with the increase of joint thickness. This is because that with the increase of joint filling thickness, joints are more prone to damage, deformation and failure under impact compression. Thus, for a relative lager joint filling thickness, the energy used for damage and failure of jointed rock specimens is smaller, that is, the energy dissipation ratio is smaller.

\section{CONCLUSIONS}

In this paper, the static and dynamic compression tests of filled jointed rock specimens are carried out by the WAW3030 universal testing machine and the SHPB device, respectively. The influences of joint filling material strength and joint filling thickness on the compression characteristics of the filled joints are accordingly analyzed. The main conclusions are as follows:

(1) The static and dynamic compression strength of the filled joint increase with the strength of the filling material while decrease with the thickness of the joint.

(2) The deformation characteristics of filled joints under the static compression and dynamic impact are related to the properties of filling materials as well as are positively related to joint thickness. Under uniaxial static compression, the failure modes of joint can be divided into two types: 1) the failure of the contact surfaces between the joint fillings and the rocks, for the jointed rock with hard fillings; 2) the failure of fillings itself, for the jointed rock with soft fillings. Under dynamic impact, the deformation of the joints with hard fillings shows certain brittleness while that of the joints with soft fillings shows certain plasticity.

(3) When the incident wave is the same, with the increasing of the filled joint thickness, the amplitude of the reflected wave gradually increases, while that of the transmitted decreases. As the strength of joint infilling increases, the amplitude of the reflected wave gradually decreases in a small range, while the amplitude of the transmitted wave increases.

(4) The energy dissipation ratio under impact compression decreases with the increasing of joint thickness while increases with the increasing of the strength of joint infillings.

\section{ACKNOWLEDGEMENTS}

This work was supported by the National Natural Science Foundation of China (No. 41902277), Open Fund of State Key Laboratory for GeoMechanics and Deep Underground Engineering, China University of Mining \& Technology 
(No. SKLGDUEK1811), Open Fund of Key Laboratory of Geological Hazards Mitigation for Mountainous Highway and Waterway,Chongqing Jiaotong University (No. kfxm2018-09) and the Natural Science Basic Research Plan in Shaanxi Province (No. 2019-JQ689).

Author's Contributions: Conceptualization, S Chai and H Wang; Methodology, S Chai, L Yu and E Abi; Investigation, S Chai and H Wang; Writing original - draft, S Chai and H Wang; Writing - review \& editing, S Chai and J Shi; Funding acquisition, S Chai; Resources, S Chai and L Yu; Supervision, S Chai.

Editor: Marcílio Alves.

\section{References}

Achenbach, J.D. (1973). Wave propagation in elastic solid. North-Holland, Amsterdam.

Amalokwu, K.; Best, A.I.; Chapman, M. (2016). Effects of aligned fractures on the response of velocity and attenuation ratios to water saturation variation: a laboratory study using synthetic sandstones. Geophysical Prospecting, 64(4), 942-957.

Atapour, H.; Moosavi, M. (2013). Some effects of shearing velocity on the shear stress-deformation behaviour of hard-soft artificial material interfaces. Geotechnical and Geological Engineering, 31(5), 1603-1615.

Atapour, H.; Moosavi, M. (2014). The influence of shearing velocity on shear behavior of artificial joints. Rock Mechanics and Rock Engineering, 47(5), 1745-1761.

Bandis, S.C.; Lumsden, A.C.; Barton, N.R. (1983). Fundamentals of rock fracture deformation. International Journal of Rock Mechanics and Mining Sciences and Geomechanics Abstracts, 20(6), 249-268.

Barton, N. (1973). Rock mechanics review, the shear strength of rock and rock joints. International Journal of Rock Mechanics and Mining Sciences and Geomechanics Abstracts, 13(9), 255-279.

Chen, X,; Li, J.C.; Cai, M.F.; Zou, Y.; Zhao, J. (2014). Experimental study on wave propagation across a rock joint with rough surface. Rock Mechanics and Rock Engineering. 2014, 48(6), 2225-2234.

Jahanian, H.; Sadaghiani. M.H. (2014). Experimental study on the shear strength of sandy clay infilled regular rough rock joints. Rock Mechanics and Rock Engineering, 48(3), 907-922.

Li, H.B; Feng, H.P.; Liu, B. (2006). Experimental studies on mechanical properties of rock joints under dynamic loading. Key Engineering Materials, 2435-2440.

Li, J.C.; Li, N.N.; Li, H.B.; Zhao, J. (2017). An SHPB test study on wave propagation across rock masses with different contact area ratios of joint. International journal of impact engineering, 105(6), 109-116.

Li, J.C.; Ma, G.W. (2009). Experimental study of stress wave propagation across a filled rock joint. International Journal of Rock Mechanics and Mining Sciences, 46(1), 471-478.

Li, J.C.; Ma, G.W.; Huang, X. (2010). Analysis of wave propagation through a filled rock joint. Rock Mechanics and Rock Engineering, 43(6), 789-798.

Li, J.C.; Rong, L.F.; Li, H.B.; Hong, S.N. (2019). An SHPB test study on stress wave energy attenuation in jointed rock masses. Rock Mechanics and Rock Engineering, 52(2), 403-420.

Liu, H.Y.; Su, T.M. (2016). A dynamic damage constitutive model for a rock mass with non-persistent joints under uniaxial compression. Mechanics Research Communications, 77, 12-20.

Liu, H.Y.; Zhang, L.M. (2015). A damage constitutive model for rock mass with non-persistently closed joints under uniaxial compression,Arabian Journal for Science and Engineering, 40(1), 3107-3117.

Liu, X.Y.; Liu, A.H.; Li, X.B. (2014). Experimental study of columnar jointed sand-stont-like material with preset filling. Chinese Journal of Rock Mechanics and Engineering, 33(4), 772-777.

Malama, B.; Kulatilake, P.H.S.W. (2003). Models for normal fracture deformation under compressive loading. International Journal of Rock Mechanics and Mining Sciences and Geomechanics Abstracts, 40(6), 893-901. 
Papaliangas, T.; Hencher, S.R.; Lumsden, A.C. (1993). The effect of frictional fill thickness on the shear-strength of rock discontinuities. International Journal of Rock Mechanics and Mining Sciences, 30(2), 81-91

Singh, T.N.; Verma, A.K.; Kumar, T. (2011). Influence of shear velocity on frictional characteristics of rock surface. Journal of Earth System Science, 120(1), 183-191.

Song, L.; Hu, S.S. (2005). Two-wave and three-wave method in SHPB data processing. Explosion and Shock Waves, 25(4), 368373.

Tian W.; Han N. (2017). Mechanical properties of rock specimens containing pre-existing flaws with 3D printed materials. Strain, 53(6), 1-13.

Wang, T.T.; Shang, B. (2014). Three-Wave Mutual-Checking Method for Data Processing of SHPB Experiments of Concrete. Journal of Mechanics, 30(5), 5-10.

Wu, N.; Zhu, Z.D.; Zhang, C.; Luo, Z.H. (2019). Dynamic behavior of rock joint under different impact loads. KSCE Journal of Civil Engineering, 23(2), 541-548.

Wu, W.; Li, J.C.; Zhao, J. (2014). Role of filling materials in a P-wave interaction with a rock fracture. Engineering Geology, 172:77-84.

Wu, W.; Zhao, J. (2015). Effect of water content on P-wave attenuation across a rock fracture filled with granular materials. Rock Mechanics and Rock Engineering, 48(2), 867-871.

Wu, W.; Zhu, J.B.; Zhao, J. (2013). Dynamic response of a rock fracture filled with viscoelastic materials. Engineering Geology, 160(2), 1-7.

Yang, S.Q.; Jing, H.W.; Xu, T. (2014). Mechanical behavior and failure analysis of brittle sandstone specimens containing combined flaws under uniaxial compression. Journal of Central South of University, 21(5), 2059-2073.

Yang S.Q; Tian, W.L.; Huang, Y.H.; Ranjith, P.G.; Yang, J. (2016). An experimental and numerical study on cracking behavior of brittle sandstone containing two non-coplanar fissures under uniaxial compression. Rock Mechanics and Rock Engineering, 49(4), 1497-1515.

Yu, J.; Chen, X.; Cai, Y.Y.; Li, H. (2016). Triaxial test research on mechanical properties and permeability of sandstone with a single joint filled with gypsum. KSCE Journal of Civil Engineering, 20(6), 2243-2252.

Zhang, B.; Li, S.C.; Zhang, D.F. (2012). Uniaxial compression mechanical property test,fracture and damage analysis of similar material of jointed rock mass with filled cracks. Rock and Soil Mechanics, 33(6), 1647-1652.

Zhang, L.M.; Lv, S.R.; Liu, HY. (2013). Test study on dynamic mechanical property of jointed rock mass. Advanced Materials Research, 868, 282-286.

Zhao, J. (1997a). Joint surface matching and shear strength part A: joint matching coefficient (JMC). International Journal of Rock Mechanics and Mining Sciences, 34(2), 173-178.

Zhao, J. (1997b). Joint surface matching and shear strength part B: JRC-JMC shear strength criterion. International Journal of Rock Mechanics and Mining Sciences, 34(2), 179-185.

Zhou, X.P.; Cheng, H.; Feng, Y.F. (2013). An experimental study of crack coalescence behavior in rock-like materials containing multiple flaws under uniaxial compression. Rock Mechanics and Rock Engineering, 47(6), 1961-1986. 